\title{
A Engineering Discipline Awareness Workshop for Pre-Service STEM Teach- ers
}

Dr. Fernando Garcia Gonzalez, Florida Golf Coast University

Dr. Fernando Gonzalez joined FGCU as an Assistant Professor in the Computer Engineering Program in the fall of 2013. Previously he was an Assistant Professor within the Engineering, Math, and Physics Department at Texas A\&M International University in Laredo, Texas. Prior to that he was a Technical Staff Member (researcher) for the U.S. Department of Energy at Los Alamos National Laboratory in Los Alamos, New Mexico. Dr. Gonzalez was also a faculty member in the Electrical and Computer Engineering Department of the University of Central Florida. Dr. Gonzalez graduated from the University of Illinois in 1997 with a Ph.D. in Electrical Engineering. He received his Master's degree in Electrical Engineering and his Bachelor's degree in Computer Science from Florida International University in 1992 and 1989. Dr. Gonzalez research interest includes the intelligent control of large scale autonomous systems, autonomous vehicles, discrete-event modeling and simulation and human signature verification. While at UCF Dr. Gonzalez founded the University of Central Florida Robotics Laboratory and was director until he moved to New Mexico. He was also a member of the faculty senate at UCF. Dr. Gonzalez has numerous conference and journal publications.

\section{Mr. Gerardo Javier Pinzon PE, Texas A\&M International University}

Mr. Pinzon is the STEM Advisor and Laboratory Manager at Texas A\&M International University (TAMIU). He is currently pursuing a PhD in Environmental Engineering. He holds a Master of Environmental Engineering from Texas A\&M University at Kingsville (TAMUK), a Master of Business Administration from the University of Texas at Austin and a Bachelor of Science in Mechanical Engineering from the University of Texas at Austin. He is also a Professional Engineer registered in the State of Texas.

\section{Dr. Anju Gupta, \\ Dr. Pablo Biswas, Texas A\&M International University}

Dr. Pablo Biswas received Ph.D. and M.S. in in Industrial Engineering from Louisiana State University, Baton Rouge, Louisiana, and B.S. in Mechanical Engineering Bangladesh University of Engineering and Technology, Dhaka, Bangladesh. He is an Assistant Professor of Engineering at Texas A\&M International University, Laredo, TX. Dr. Biswas's research interest is in supply chain management, inventory control, lean production systems, and information systems. 


\title{
An Engineering Discipline Awareness Workshop for Pre-Service STEM Teachers
}

\begin{abstract}
The Engineering Discipline Awareness Workshop for Pre-Service STEM Teachers was designed for future high school teachers in STEM fields to provide awareness of the different engineering disciplines. The goal is to create engineering interest among the students graduating from high school and entering higher education. The strategy is to create engineering awareness in the local high school STEM teachers so that they in turn pass that interest onto their own students. This workshop is part of the Texas A\&M University Engineering Experiment Stations (TEES) Outreach Strategy Team's Pilot Program. Situated on the border with Mexico, Texas A\&M International University (TAMIU), a Member of the Texas A\&M University System, serves predominantly Hispanic population by providing academic services to a high number of economically disadvantaged and first-generation students. The majority of the teachers in Laredo, Texas received their education from TAMIU, targeting the pre-service teachers at TAMIU will expand our future teachers' knowledge of the different engineering disciplines, and aid in TAMIU’s Engineering recruitment program.

Three professors from different engineering disciplines each provided an entire day curriculum dedicated to their particular discipline. Each presentation was divided into three modules, an introduction to the particular engineering field, some basic engineering theory and a hands-on engineering exercise. In this paper we present details of the three engineering disciplines presented to the participants which include chemical, electrical and systems engineering.
\end{abstract}

\section{Introduction}

Hispanics are the fastest-growing and youngest ethnic group in the United States. It is estimated that Hispanics will comprise 30 percent of the U.S. population by the year 2040 and will become the largest ethnic group by then. Therefore, it is essential to provide perceptions of different engineering disciplines to the future high school teachers in STEM disciplines. The pre-service STEM teachers' workshop was designed for future high school teachers in STEM fields to provide awareness in the engineering disciplines. Therefore, three professors from different engineering disciplines provided an entire day curriculum for each day of the workshop. The workshops were funded by a grant from the Department of Education, award number \# P031C110118 titled "Serving Youth in Science, Technology, Engineering, and Mathematics (SYSTEM)" in collaboration with the Texas A\&M University Engineering Experiment Stations (TEES) Outreach Strategy Team’s Pilot Program.

\subsection{Background Information}

The university student body comprises of 90\% Hispanic students of which most are economically disadvantaged and are under prepared when entering the university. The City of Laredo sits on the boarder of Mexico and has a much lower per capita income when compared to both the state and national averages. Data from the U.S. Census Bureau 2010 and the 2005-2009 
American Community Survey 5-Year Estimates shows that the City of Laredo has the following characteristics:

- The Hispanic population is $94 \%$

- The per capita income is $\$ 13,941$ compared to $\$ 27,041$ nationally.

- The percent of residents living at or below the poverty income level is $29 \%$ compare to $14 \%$ nationally.

- Over $22.5 \%$ of the population has less than a $9^{\text {th }}$ grade education compared to $6.4 \%$ nationally.

- Only $12.8 \%$ hold a Bachelor's degree compared to $17.4 \%$ nationally.

- Only 5\% hold a master's or higher degree compared to $10.1 \%$ nationally.

This presents a challenge in motivating our graduating high school students to pursue a career in engineering.

\subsection{The Problem Addressed by this Workshop}

This data indicates there is a challenge in this city to encourage students completing their high school to consider a career in engineering. While we recognize we have this problem we also recognize that we have control over the solution. Since TAMIU graduates the majority of the teachers entering the local schools we have some control over what these new teachers teach their student by what we can teach them. Most pre-service teachers in our program are eager to learn about engineering but just need an avenue to learn. Our approach to this problem is to inform the pre-service teachers about the fields of engineering with the hopes that they will intern inform and encourage their younger students about these fields.

\subsection{The details of the Workshop}

The workshop consisted of 5 full days. Three of the days were dedicated to the three fields of engineering, chemical, electrical and systems engineering. Each engineering day consisted of three parts. The first was an introduction to the field including salary expectations, the type of work they do and any other pertinent information the presenter finds valuable. The second part included a short presentation of some of the fundamental concepts in that field. The last part included a hands-on project where the participants got to perform some actual engineering work. The rest of this paper includes the details of the three engineering parts of the workshop.

The workshop consisted of the following. In day 1 the participants were introduced to the general field of engineering. They were presented with the engineering design process. In days 2 through 4 the participants were presented with the specific engineering fields which included chemical engineering in day 2, electrical engineering in day 3 and systems engineering in day 4 . And finally in day 5 they were given some tours of local industry in the morning and they were given lunch while listening to prominent local engineers speaking about their work as an engineer in the afternoon. 
The participants were evaluated before and after participating in the workshop. They were given a survey about their perceptions of the engineering fields before participating in the workshop and then after they completed the workshop. The survey asked the same questions.

\section{The Engineering Design Process}

In an effort to engulf the participants in the field of engineering, several presentations on the understanding of the core concepts of engineering foundations were presented. The first lecture was a presentation titled "Engineering as a Profession" in which the engineering career was highlighted by showcasing the different disciplines of engineering. Following this presentation, the participants were asked to select two engineering disciplines and research them using the internet. They had to answers some questions such as what types of industry employs them, what are their salary expectations and what level of education they require. This gave them a perspective of the discipline and allowed them to get familiar with the field. This was then followed by a presentation on what is required to become a licensed Professional Engineer (PE). This presentation was on the education, examination and experience required to obtain a Professional Engineering license.

In the afternoon session the participants were introduced to the Engineering Design Process. They had to solve a problem given to them by the presenter using the first 6 of the 10 step engineering design process presented below:

1. Define the problem.

2. Acquire pertinent data.

3. Identify constraints.

4. Develop alternative solutions.

5. Select a solution based on analysis of alternatives.

6. Communicate the results.

After the lecture presentation the participants were asked to work in teams of three on the following:

- Dorms are often designed to accommodate two students and normally are equipped with two desks, two closets, two beds, two shelving units, and one dresser.

- What can we do to have better space utilization?

- If additional furniture is permitted such as a refrigerator or a microwave oven, the space will be even more crowded.

The participants were given the following lead into the engineering solution to this example:

- $\quad$ Define the problem - Better dorm space utilization

- Acquire pertinent data - size of room, how many students

- Identify constraints -

o No major modifications to structure

o limited to current room size

o Limited money and time $(<\$ 500)$ 
o Safety

o Bed size to fit student - 78' x 36"

0 Must be free standing and not affect existing structure of the room

- Alternate Solution and Analysis -

o Develop alternative solutions - brainstorm 3 to 5 solutions

o Elevate the beds (loft) by purchasing a prefabricated loft system

o Rent two rooms and cut a connecting door

o Purchase a lofted bed from a graduating senior

o Select a solution based on analysis of alternatives

0 how to re-arrange other furniture

o Ensure safety, utilization and comfort.

- Criteria are weighted according to importance. Trades could be made.
o Ease of assembly
$35 \%$
o Functionality $25 \%$
(includes accessibility to the loft, effective use of space
o Cost $25 \%$ (includes cost of materials and tools. This is also a constraint
o Stability $15 \%$
(includes consideration of structure integrity, safety and freestanding capability)

- A good solution will always have some creativity in it.

The participants were given a couple of hours to work on their ideas. The purpose of this exercise was for them to grasp the steps required to complete an engineering project.

\section{Chemical Engineering Workshop}

The highlights of the Chemical Engineering workshop were: 1) familiarize the pre-service teachers with the chemical engineering curriculum and the profession, 2) introduce the concepts of basic unit operations, block and process flow diagrams, materials, and energy balances, and 3) engage them on a hands-on laboratory activity to produce their own biodiesel. The laboratory activity was supplemented with a question set that includes calculations appropriate for an introductory-level course, and flow diagrams for the process.

\subsection{The First Module}

This one-day workshop included three modules. In the first module, basic unit operations were discussed, followed by the generation of block diagrams. In addition, the concepts session included a pre-workshop survey, introduction to the chemical engineering curriculum, and career opportunities. The participants were also exposed to a variety of senior design topics to demonstrate the multidisciplinary nature of the field. The concept of recycling was introduced, and the pre-service teachers modified the streams in their generated block diagrams to "avoid waste". Activities included proposing a flow diagram of a simple two-step process, identifying the basic components of process flow diagrams and guessing the name of unknown process. 


\subsection{The Second Module}

The second module covered the mass based material and energy balances. The concept of conservation of mass was introduced using mass-based chemical reactions, which was further applied to a unit operation problem using the block diagram generated in the first module.

\subsection{The Third Module}

The third laboratory module provided an overview of the scientific and engineering aspects of biodiesel production supplemented with a hands-on-activity on the biodiesel production using soybean, and waste vegetable oil obtained from the TAMIU diner. Flow diagrams of the process were generated followed by simple material balance calculations.

\subsection{Specific Evaluations for the Chemical Engineering Session}

At the end of the chemical engineering workshop, the pre-service teachers were surveyed for their knowledge on the chemical engineering program, their opinion of the workshop, Figure 1 and to provide comments, Figure 2.

\begin{tabular}{|c|c|}
\hline Pre-workshop Survey Questions & Common Responses \\
\hline Expectations from the workshop & $\begin{array}{l}\text { Basic understanding of the field, preparing to discuss with the } \\
\text { future students- prerequisites, classes to take, career } \\
\text { opportunities, applications and usefulness in daily life }\end{array}$ \\
\hline What is chemical engineering & $\begin{array}{l}\text { Solutions to fuel, oil, plastics, water } \\
\text { Studying chemicals- mixing, different types, design, chemical } \\
\text { products, handle dangerous chemicals like acid, experiment with } \\
\text { liquids, for humans, ecosystem, and environment }\end{array}$ \\
\hline Topics in Chemical Engineering & $\begin{array}{l}\text { Oil field, environment, chemistry, water supply, production-food } \\
\text { conservatives, colors, makeup, new and efficient product } \\
\text { development, biofuels, environment, energy, disposal of fluids, } \\
\text { medicine, soap, hair-spray }\end{array}$ \\
\hline Employment sectors & $\begin{array}{l}\text { Manufacturing, State government, Oil, fuel, engine, water plant, } \\
\text { NASA, research, chemist, cosmetics, }\end{array}$ \\
\hline What is Biodiesel & $\begin{array}{l}\text { Type of oil, biodegradable diesel, environment-related, plant } \\
\text { product, making of petroleum, organic gasoline, alternate fuel } \\
\text { resource, life/body related, synthetic, renewable oil }\end{array}$ \\
\hline
\end{tabular}

Figure 1: Chemical Engineering specific survey results

" The information give during the presentations was really good. It helped me understand what chemical engineering is and what chemical engineers do. The activities were the things that helped me the most to understand this discipline of engineering. The hands on activity was also really interesting. It helped me understand how several things, such as waste oil, can be recycled"

“I have a much better understanding of chemical engineers" "Overall it was a very productive and education opportunity" "Fun great, interesting, appealing"

Figure 2: Participant's comments from survey. 
Post-workshop assessments suggest the participants obtained an improved understanding of the chemical engineering curriculum and careers, process flow diagrams and material balance, and biodiesel production.

\section{Electrical Engineering Workshop}

The goals of this workshop were to familiarize the participants with the profession, motivate them by showing the wide range of work that electrical engineers do and to give them some hands-on experience in electronics and circuits. The workshop was divided into 3 parts. In the morning session they were first presented with a description of the electrical engineering profession then they were presented with some fundamental electrical engineering concepts. In the afternoon session they worked on two hands-on projects.

\subsection{What is Electrical Engineering?}

The first part presented in the morning session started with an introduction to the type of work electrical engineers typically do and their salary expectations. It contained lectures on the different fields of electrical engineering. The topics included what is electrical engineering, what are the different fields of electrical engineering, what are the different types of electrical engineering professions, salary expectation for the different field in the profession, and some of the latest research in the field. This material was presented with the goal of motivating the students to think about this field for their future studies in higher education.

\subsection{Concepts of Electrical Engineering}

The second part was also presented in the morning session. It included some basic fundamental electrical engineering concepts including the concept of electricity looking at it from a physics point of view, concepts on electromagnetic fields, the water flow analogy, and analog versus digital electronics. Next an extensive lecture on how computers are made from the basic atom to the final computer was presented. This was intended to be interesting to the participants and to allow them to learn that what is perhaps the most important device invented in modern history falls entirely in the field of electrical engineering. Specifically it included the flow of current from the point of view of the electrons flowing through the outer orbits of the atoms; what are semiconductor materials and why it's important to this devise; how the semiconductor material is used to make field effect transistors (FET) ${ }^{3}$ which is used as an electronic switch; how this electronic switch is used to make logic gates; how the logic gates are used to make flip-flops, memory cells, decoders, encoders, digital adders, and the arithmetic logic unit (ALU) ${ }^{2}$; and finally how all this is programmed using software development. Next we looked at Ohms Law ${ }^{3}$ and they were presented with some simple circuit analysis techniques. Finally they were presented with resistors, capacitors, inductors, light emitting diodes and other electronic components ${ }^{3}$.

Example:

The participants were introduced to Ohm's law.

$V=I R$ 
where $V$ is the voltage, $I$ is the current and $R$ is the resistance. Using Ohm's law the students learned how to perform a simple circuit analysis. In Figure 3 (a), a simple light emitting diode (LED) is shown. The triangular component is the LED which emits light when 0.7 volts is applied across it, the zigzag component is the resister which is used to burn off any excess voltage greater than 0.7 volts so the LED does not burn, and the circle is the power source which is providing 10 volts. Current travels from the positive $(+)$ side of the source to the negative $(-)$ side. In Figure 3 (b) the circuit analysis is shown. Ohm's law was solved for the current

$I=\frac{V}{R}$

then we introduced the power law

$P=I V$

which states the power dissipated by a component is the product of the voltage and the current. The values were plugged into the equations and we computed the power dissipated by the resister and the diode and the power delivered by the power source.

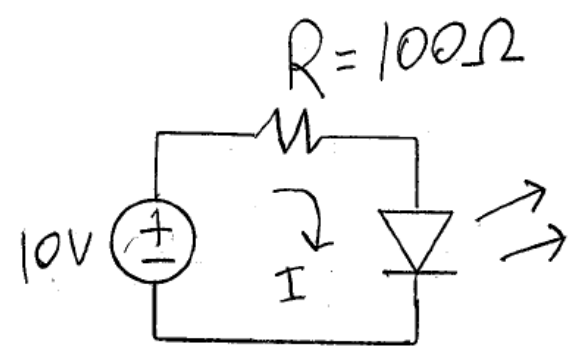

a

$$
\begin{aligned}
& I=\frac{v-0.7}{R}=\frac{10-0.7}{100}=93 m A \\
& P_{r}=I V_{r}=93 m A(10-0.7)=0.87 \text { Watts } \\
& P_{l}=I V_{l}=93 m A(0.7)=0.07 \quad \text { Watts } \\
& P_{\text {total }}=I V=93 m A(10)=0.93 \text { Watts }
\end{aligned}
$$

$\mathrm{b}$

Figure 3: (a) A simple light emitting diode example circuit, (b) the corresponding circuit analysis.

\subsection{Hands-on Circuit Analysis}

The third hands-on part was presented in the afternoon and was divided into two sections. First the students were given an electric circuits experiment kit suited for children from 8 years of age, the Snap Circuits PRO SC-500 ${ }^{1}$, see Figure 4. This kit includes many different electronic components and a circuit recipe book that includes the design of 500 different circuits, see Figure 5. The LED circuit in Figure 3 (a) was implemented using the Snap kit, see Figure 6. They learned how this product, considered a toy, can introduce their future students to the basic concepts of electrical engineering at a very low cost with minimal knowledge from the teacher. 


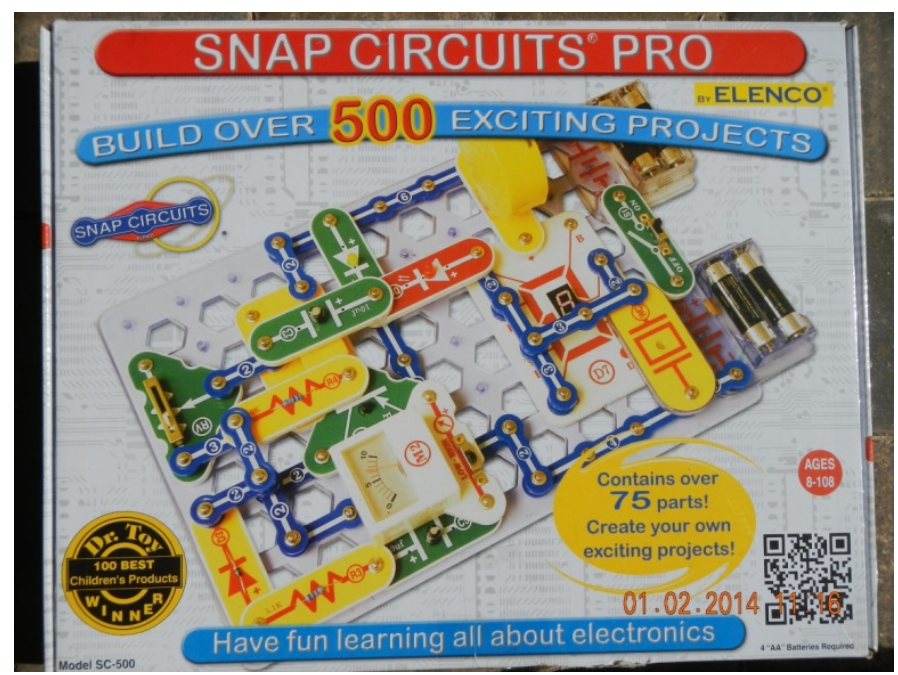

Figure 4: The Snap Circuits PRO SC-500 kit.

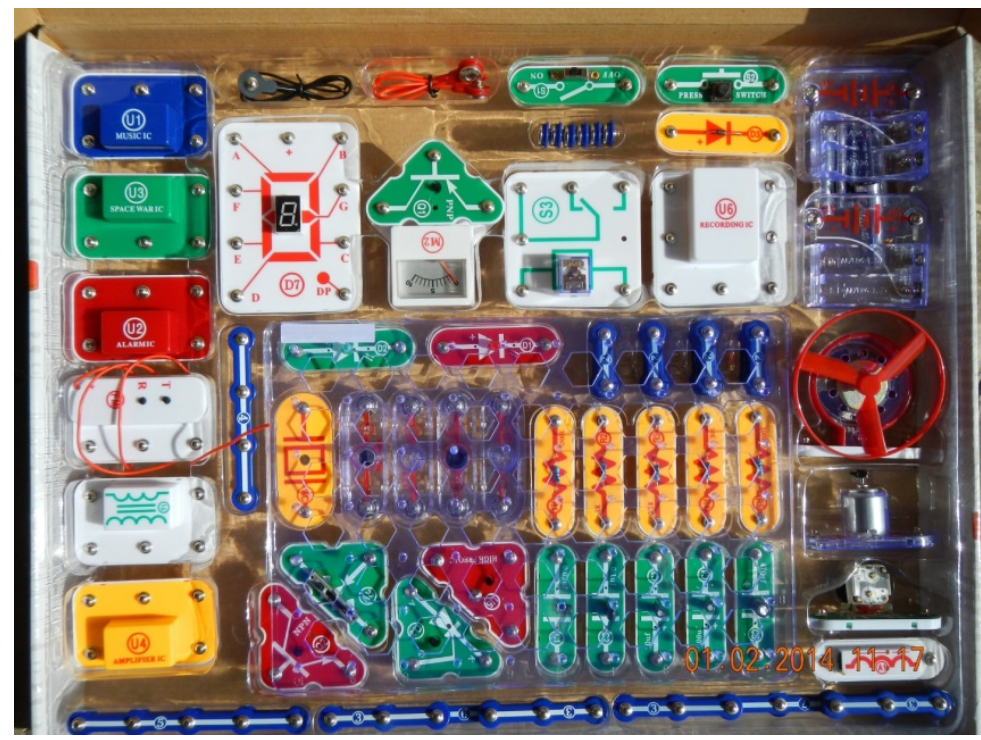

Figure 5: The snap kits includes electronic components suficient to produce 500 experiments.

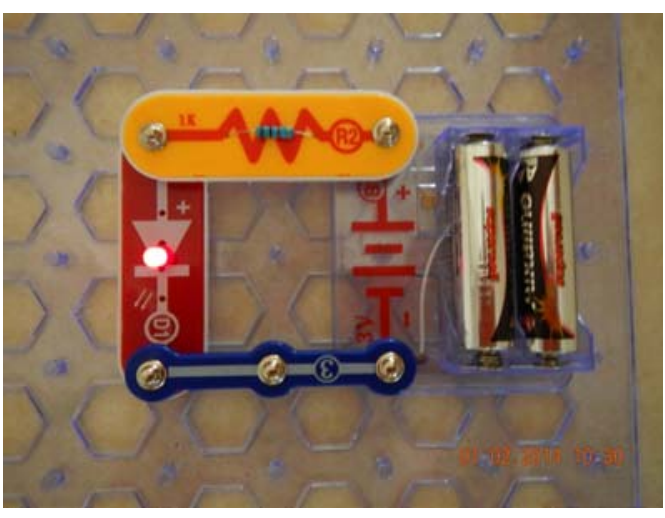

Figure 6: The LED circuit assembled using the Snap kit. 
In the second section the students built the circuit in Figure 3 (a) consisting of an LED and a resistor and measured the voltage across the two devises and the current in the wire and compared it to their computed values. They implemented the circuit using the professional breadboards that our university student's use, see Figure 7. This allowed them to see how actual electrical engineers work.

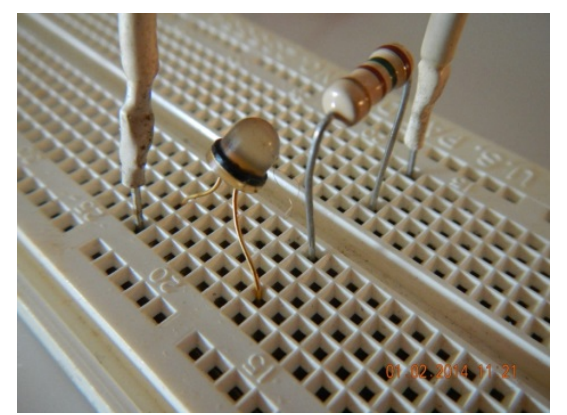

Figure 7: The LED circuit implemented on a breadboard. The spherical device is the LED, the cylindrical device with the color bands is the resister, the wires are connected to the power source, and the white board with square holes is the breadboard.

\section{Systems Engineering Workshop}

In day three of the workshop, the participants were presented the concepts of systems engineering and its application. The workshop sessions were divided into two parts, the concepts of systems engineering and some hands-on activities to design and build a DVD rental information system from scratch using Microsoft Access 2010. Thus the participants not only learned the concepts of the systems engineering, but they also learned how systems are built.

\subsection{Concept of Systems Engineering}

In the beginning of the morning session, the participants of the workshop were introduced to the term systems engineering, which is a recent addition to the engineering discipline. Therefore, it was necessary to present problems like "what is a system," and "what is systems engineering." According to the NASA Systems Engineering Handbook ${ }^{7}$ and INCOSE ${ }^{6}$, "A system is a set of interconnected components, which interact with one another in an organized fashion to achieve a common goal." Systems engineering is an interdisciplinary approach to enable the realization of successful systems. It focuses on defining customer needs and required functionality early in the development cycle, documenting requirements, proceeding with design synthesis and system validation while considering the complete problem such as operations, performance, test, manufacturing, cost and schedule, training and support, and finally disposal, Blanchard and Fabrycky ${ }^{4}$, and Wasson ${ }^{5}$. Systems engineering integrates all of the disciplines and specialty groups into a team effort forming a structured development process that continues from concept to production to operation. Systems engineering considers both the business and the technical needs of all customers with the goal of providing a quality product that meets the user needs.

\subsection{Systems Development Process}

After presenting the definition of systems and systems engineering, an explanation of the system development process was presented. Systems engineering focuses on the original need of a 
system or product to the final system or product built. The systems engineering process focusses not only the entire system, but also on the full system life cycle. The systems development process is presented in Figure 8. Systems engineering brings two elements to a project that do not usually exist, a disciplined focus on the end product and a consistent vision of stakeholders' expectations independent of daily project demands, Blanchard, Fabrycky ${ }^{4}$ and Wasson ${ }^{5}$. To develop a system or product, the first step is to find the requirements that a system has to have for complete operation. To achieve the requirements, systems engineers gather all the information from the stake holders or the customers and arrange them according to importance of the functionality of the required system. Then the system operations concept is finalized and functional requirements are achieved. The functional requirements describe the function of each component that needs to be integrated for the system to work. After that, the system architecture is designed and all requirements are allocated in the required places. The system's detailed design is build and the implementation of the system is achieved. When the system is implemented, rigorous tests are conducted to verify whether all the system needs are achieved and all the functionality are working perfectly. If problems are found, they are fixed before the system is handed over to the clients/stakeholders/customers that will be using the system.

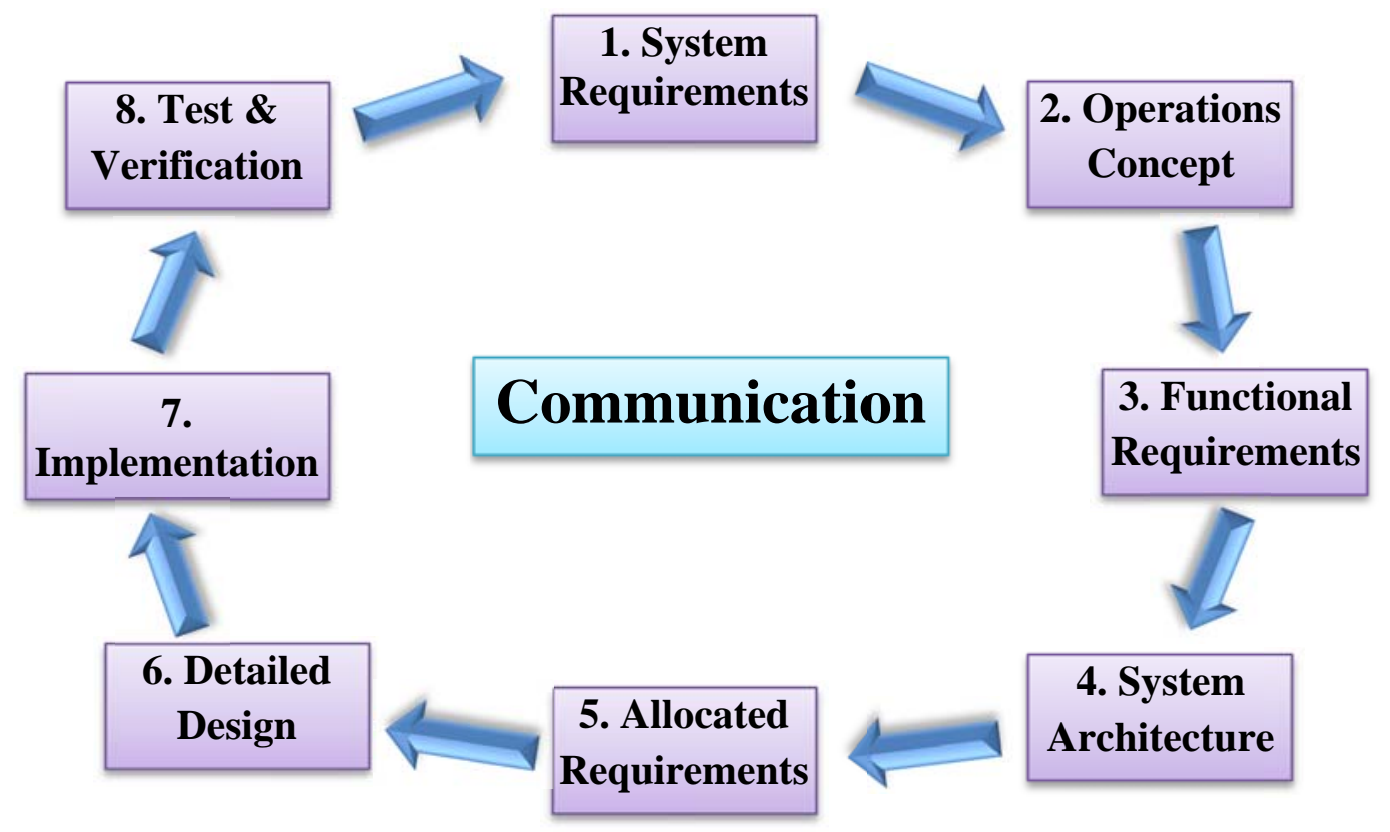

Figure 8: Systems develop process.

After describing the system development process, the different types of system development life cycle processes were presented. They included the waterfall model, the object oriented development model, the rational unified process model, the Vee model, the spiral model, the agile method, and many others. In this part of the workshop the participants learned the difference between various systems engineering life cycles and their effectiveness. Moreover, the participants learned about systems engineering contributions, the role of systems engineering in product development, building blocks of systems engineering, ethical considerations, history of systems engineering, standards, system requirements definition, system objectives, and legacy 
systems. In the afternoon session of the workshop, the participants learned how to use Microsoft Access and how it can be used to develop a system.

\subsection{Build a DVD Rental Information System using MS Access}

In this session of the workshop, the participants were provided the task to build a DVD rental system from scratch using Microsoft Access 2010. This assignment was selected because Microsoft Access has the capability to manage a database and it allows for object oriented development of the system itself. The participants were provided instructions for each step of the development process.

\subsection{Identify System Requirements}

By explaining the systems development process in the morning session, the workshop participants understood the importance of requirements identification. The participants were asked to find the required information to build a DVD rental information system, where they will be the customers or stake holders as well as the systems engineers. Upon discussion among the participants, the required information to build such a system was found to be the customer information (name, address, phone number, credit card information, date of birth, etc.), movie information (title, cast, genre, runtime, rating, format, etc.), and DVD rental information (date in, date out, rental cost, etc.). After that the functional requirements of the system were discussed. The functional requirements were (1) the need for a database to store all the information found earlier, (2) a user interface to view the information based on the movie title, customer name, etc., (3) a DVD rental user interface, and (4) an exit system.

\subsection{Creation of Database for DVD Rental System}

When the identification of the necessary requirements was completed, the workshop participants were provided an introduction to Microsoft Access 2010. This introduction consisted of creating database tables, introduction to relational database and design, database normalization, building relationship between the tables, and inserting data into the created tables. The important issue that was introduced was the database normalization and creation of relational tables by adding primary keys and foreign keys. The database normalization is a process of organizing the fields and table of a relational database to minimize the data redundancy and dependency. Figure 9 shows the relationship that was built during the workshop with the required tables for the DVD rental system. After creating the relationship and insertion of the data, the workshop focused on the user interface building. 


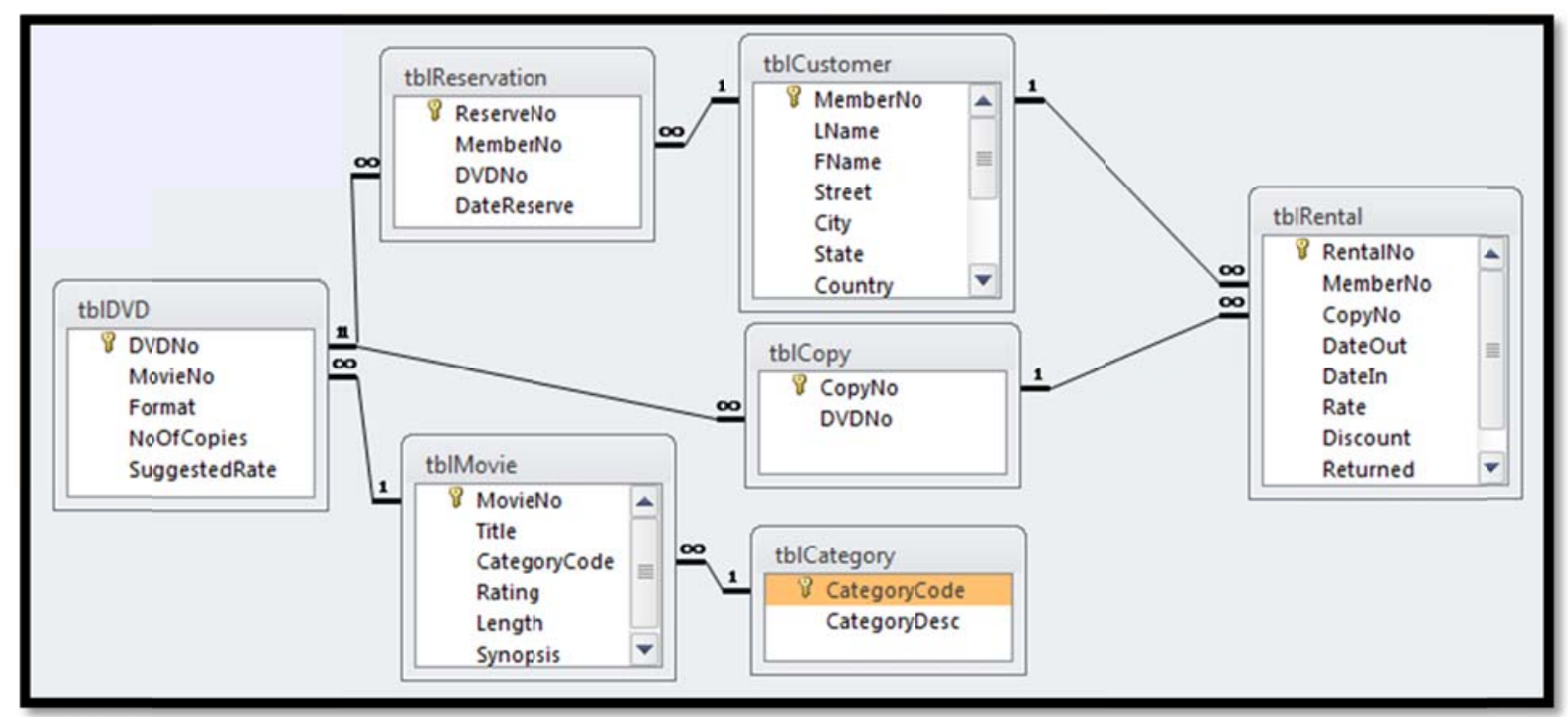

Figure 9: Database relationship for the DVD rental system

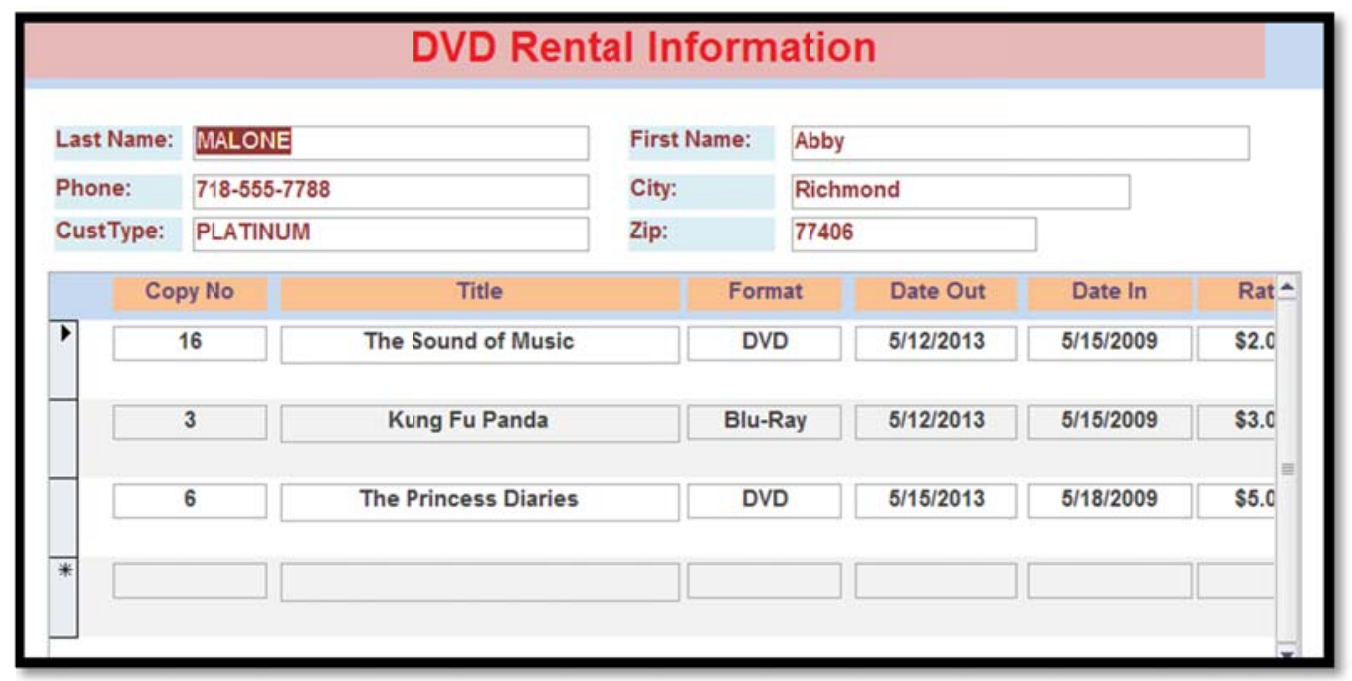

Figure 10: Sample user interface for the customer's DVD rental information.

\subsection{Creation of User Interface for DVD Rental System}

In this section, the workshop participants were introduced to form creation using the Form Wizard in MS Access. The purpose of this exercise was to enable the participants to build a simple form to view and enter data through the user interface, to build a main form including a subform to build another user interface, and to build a main form with multiple subforms. Forms provide an easy-to-use interface for entering and displaying data in a database. In addition, forms can also be used to create a main menu or switchboard for an application/system and to create a dialog box to accept user input. The Form Wizard asks detailed questions about the record sources, fields, layout, and format then creates a form based on these answers. The participants were able to modify the form using the design view and layout view. The layout view allows 
modification of the form design while viewing the data and the design view displays the form design but it does not display data, Lambert and $\operatorname{Cox}^{8}$. A sample user interface for customer rental information that was presented at the workshop is shown in Figure 10. During this process the workshop attendees also learned how to create queries using the query wizard, how to build combo boxes, command buttons, and how to create a main menu (Switchboard).

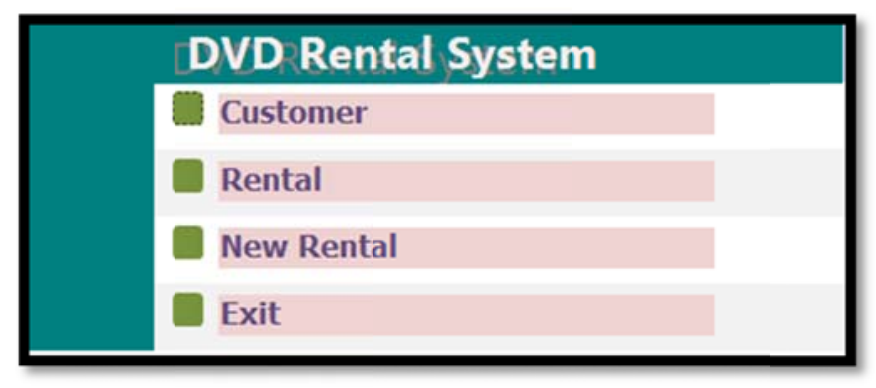

Figure 11: The complete DVD rental information system interface.

Finally, all forms were gathered together to create a DVD rental information system using the switchboard functionality of MS Access that is presented in Figure 11. At the end of the day the participants understood the concepts of systems engineering and its application to the real world by building a system on their own.

\section{Evaluation Results}

This workshop was intended to give the participants some idea of the different types of engineering fields that exist. They were not expected to learn the material well enough to be able to apply any of the engineering concepts to solve real problems. Therefore giving them a test of the material would not have produced valuable results. The end goal was to increase the number of Hispanic students entering the fields of engineering. However measuring any rate of change would have involved many more workshops to obtain a large pool of engineering knowledgeable teachers and many years for these teachers' students graduate from high school and make career decisions. This was not practical to measure. The only practical method to measure the success of the program was to give the students a survey to see how their perception of the fields of engineering changed over the course of the workshop. It was assumed that a teacher that has a good perception of these fields and has some knowledge of the difference between the engineering fields will be more likely to motivate their future students into choosing this career path.

The participants were given a survey before and after the workshop so that we would be able to compare the results and see the difference. The same questions were given in both surveys. The survey asked the participants to rank each statement as strongly agree, agree, neutral, disagree, and strongly disagree. For the analysis each rank was given a weight, see Table 1, then a weighted mean was computed with the rankings from the survey, much like the computation of grade point average. For example for the post-survey of question 1 the average was computed as $0.97 * 2+0.07 * 1=1.93$. The survey questions are listed by numbers in the charts. The questions and their question numbers are presented in Table 2. 
Table 1: Survey ranking weights.

\begin{tabular}{l|l} 
Ranking & Weight \\
\hline Strongly Agree & 2 \\
Agree & 1 \\
Neutral & 0 \\
Disagree & -1 \\
Strongly Disagree & -2
\end{tabular}

The survey questions were divided into 3 groups, questions 1 through 3 (Figure 15 through Figure 17) are related to misconceptions about engineers the participants may have had. Questions 4 through 7 (Figure 18, Figure 19, Figure 20, and Figure 21) are related to the material they learned and Questions 8 and 9 (Figure 22, Figure 23) indicate the participants desire to integrate their newly acquired engineering knowledge into their K-12 curriculum.

\section{Table 2: Survey questions and their corresponding number}

\begin{tabular}{|l|l|}
\hline Survey Question & \\
\hline Engineers are expected to work well with people & 1 \\
Engineers are expected to have good verbal/writing skills & 2 \\
Engineers are expected to have good math skills & 3 \\
I am familiar with the engineering design process & 4 \\
I am familiar with the types of problems to wich the engineering design should be applied & 5 \\
I understand the process of communicating technical information & 6 \\
I am familiar with engineering careers and disciplines & 7 \\
I believe the engineering design process should be integrated into the K-12 curriculum & 8 \\
I feel confident about integrating the engineering design process into my teaching curriculum & 9 \\
My motivation for teaching science is to prepare young people for the world of work & 10 \\
\hline
\end{tabular}

Figure 12 show that the misconceptions were clarified or at least got them to think about them by the fact that the participants changed their answers to the related questions. One can see that for the engineering related material the participants learned, all the participants went from disagreeing with the general statement that indicates they are familiar with the knowledge to more than agreeing, see Figure 13. Note all the averages are above 1.0. For the participants desire to integrate the learned material into their curriculum they went from less than agreeing to midway between agreeing and strongly agreeing see Figure 14. One can expect the participants to have a desire to integrate this material into their curriculum by the fact that they agreed to participate in this program. So this increase is actually very encouraging. It is understood that these results do not necessarily imply the influence this workshop had on the participants will results in an appreciable impact on the number of student who consider engineering when they graduate high school. Realistically to have gotten a significant impact the participants would have needed to participate in more extensive programs such as the First USA Robotics Competition. The goal of this program was to give the participants the information they need so that when an opportunity were to arise they can better educate a young student seeking career advice about the possibility of engineering as a career. The data does suggest that they obtained the knowledge they need to give such advice. 


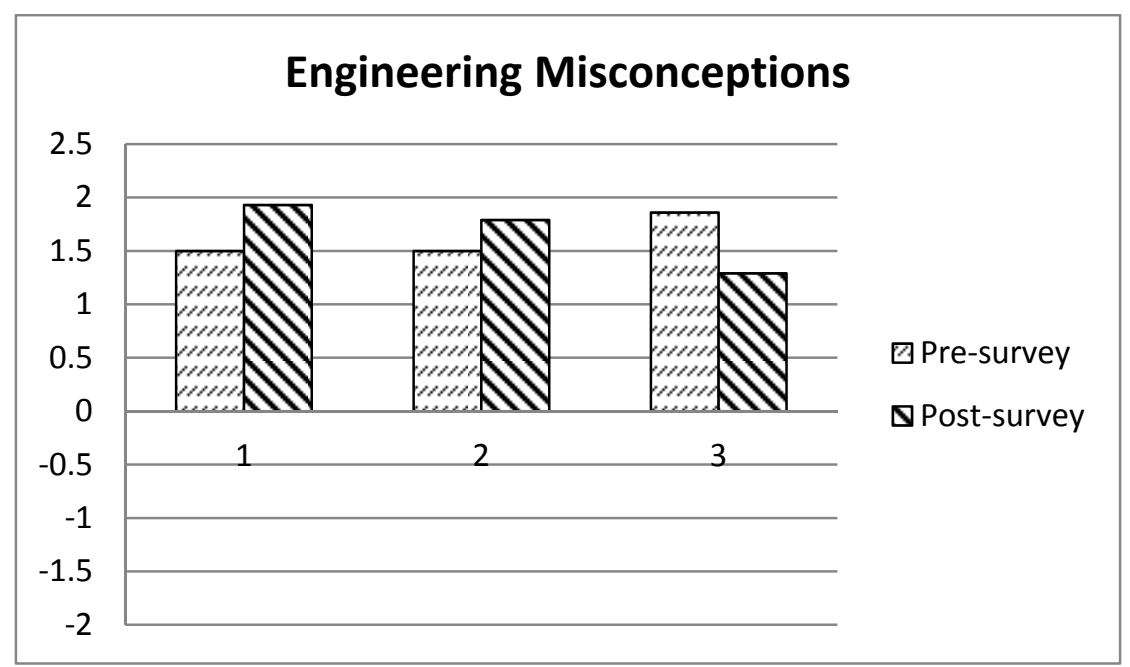

Figure 12: Engineering misconceptions

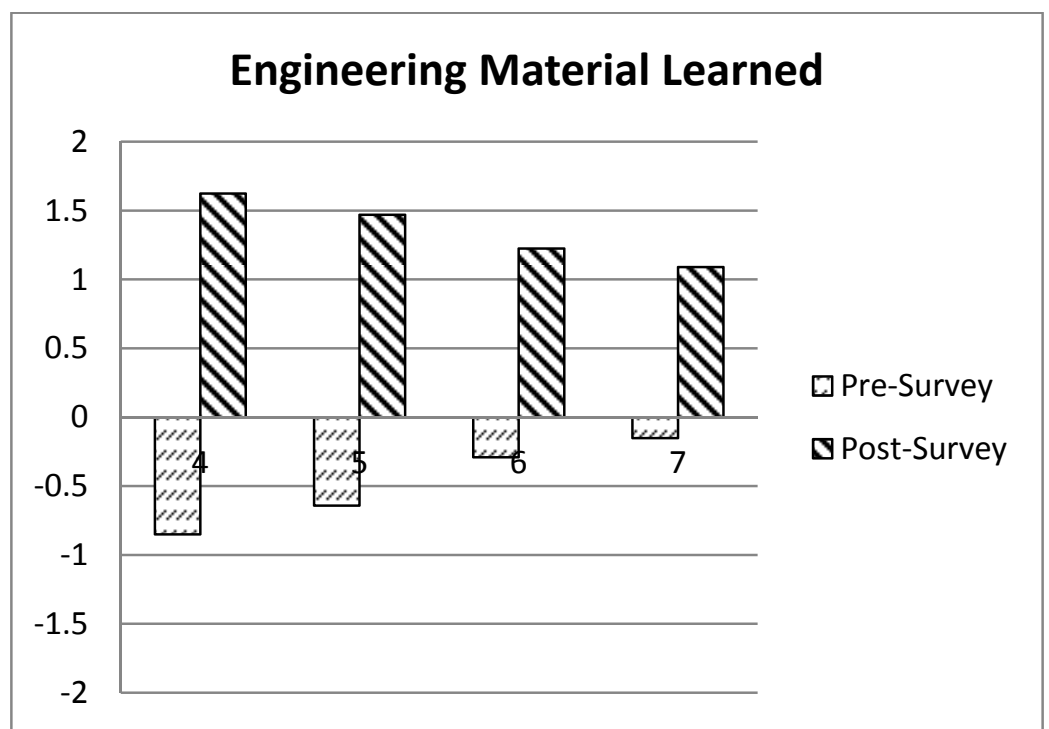

Figure 13: The engineering material the participants learned

$$
\begin{aligned}
& \text { D } \\
& \stackrel{0}{0} \\
& \mathbb{D} \\
& N \\
& \stackrel{+}{+} \\
& \mathbb{0} \\
& \overrightarrow{0}
\end{aligned}
$$




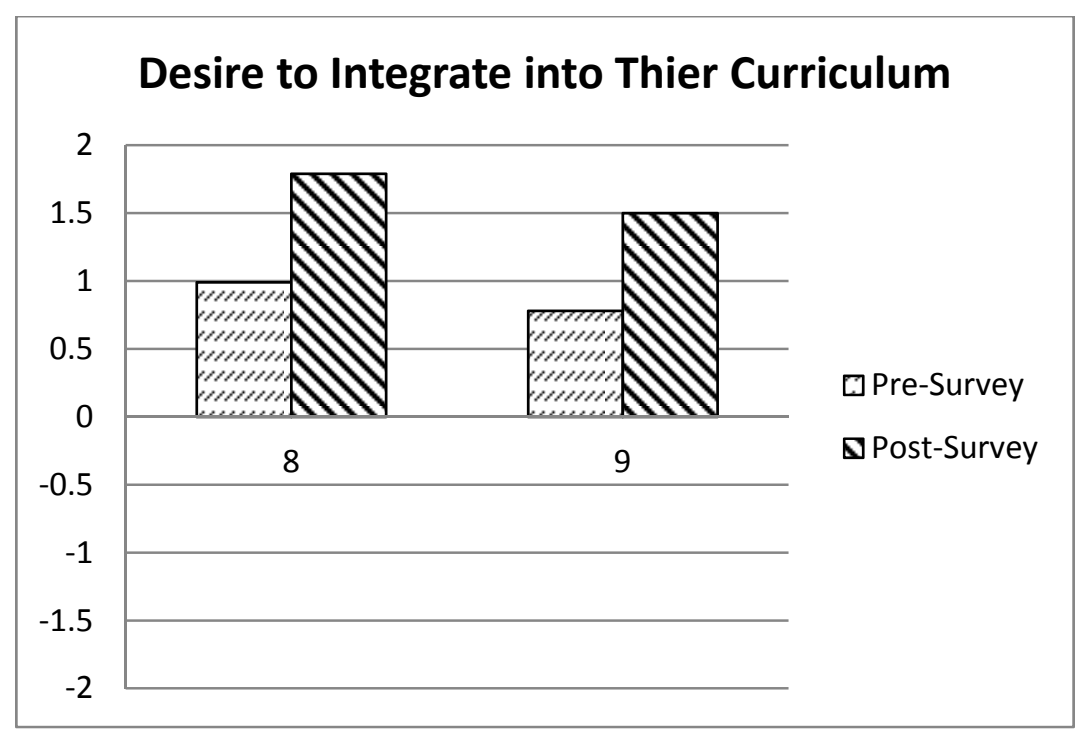

Figure 14: The desire the participants have to integrate the material into their curriculum

Figure 15 through Figure 24 present the raw data for the pre and post survey results. Post workshop surveys about the experience were also taken with the results shown in Figure 25 and Figure 26. The results indicate the participants enjoyed the workshop and found it useful.

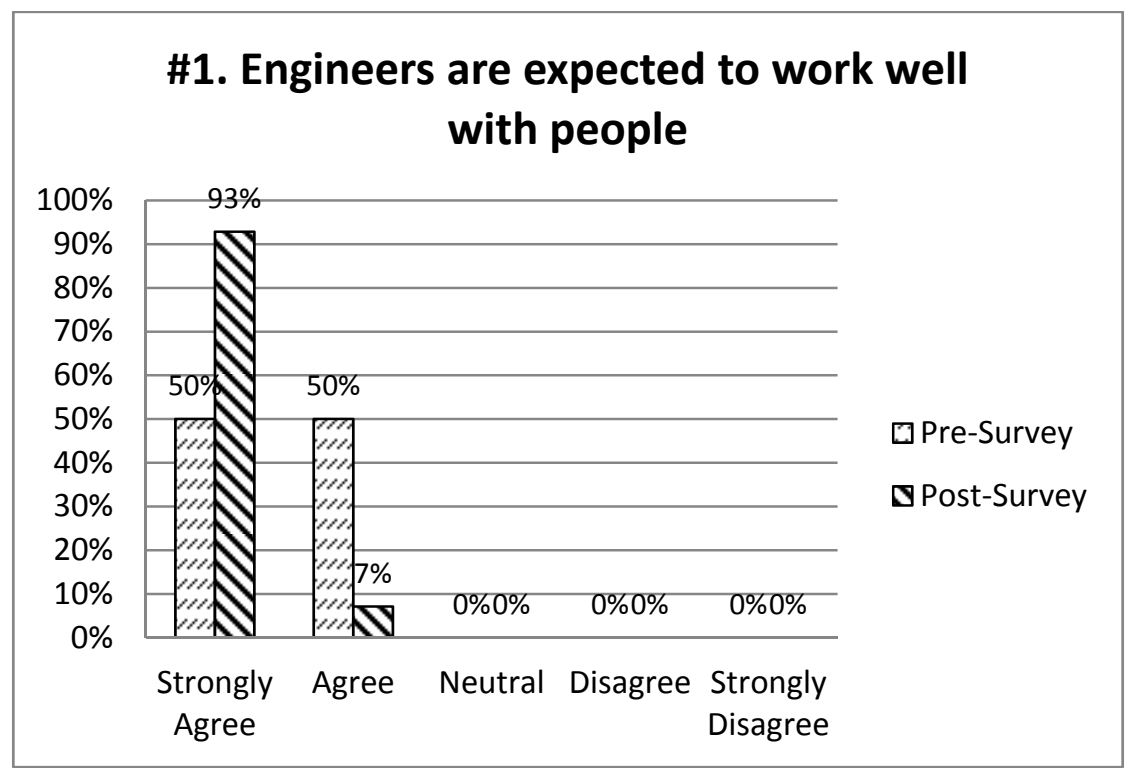

Figure 15: Survey question 1 


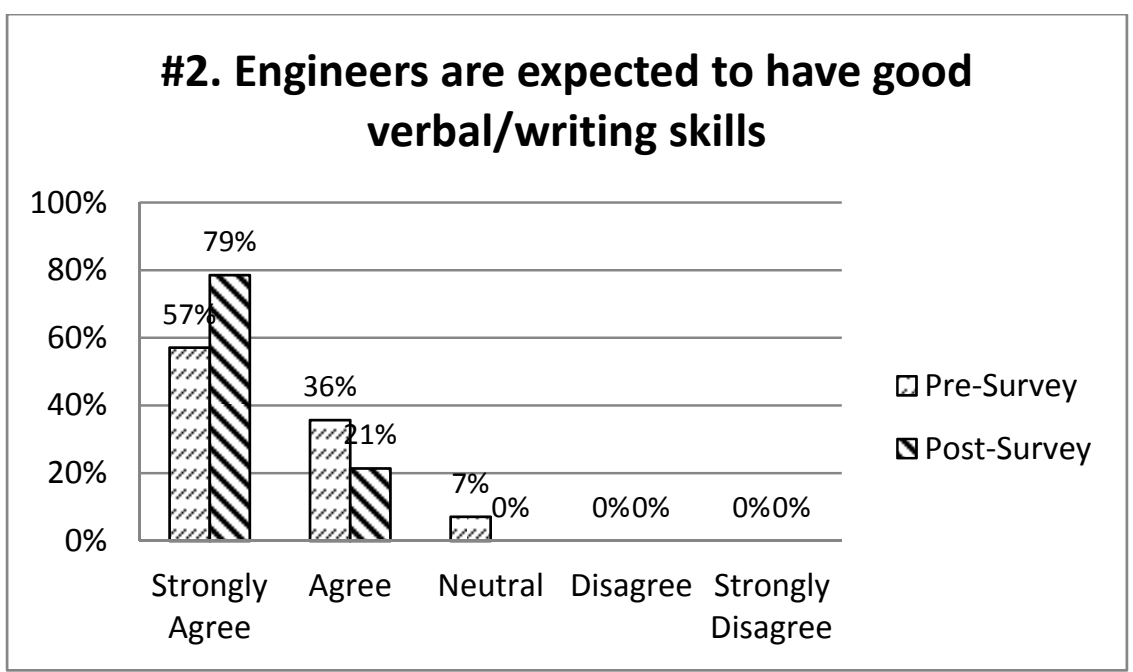

Figure 16: Survey question 2

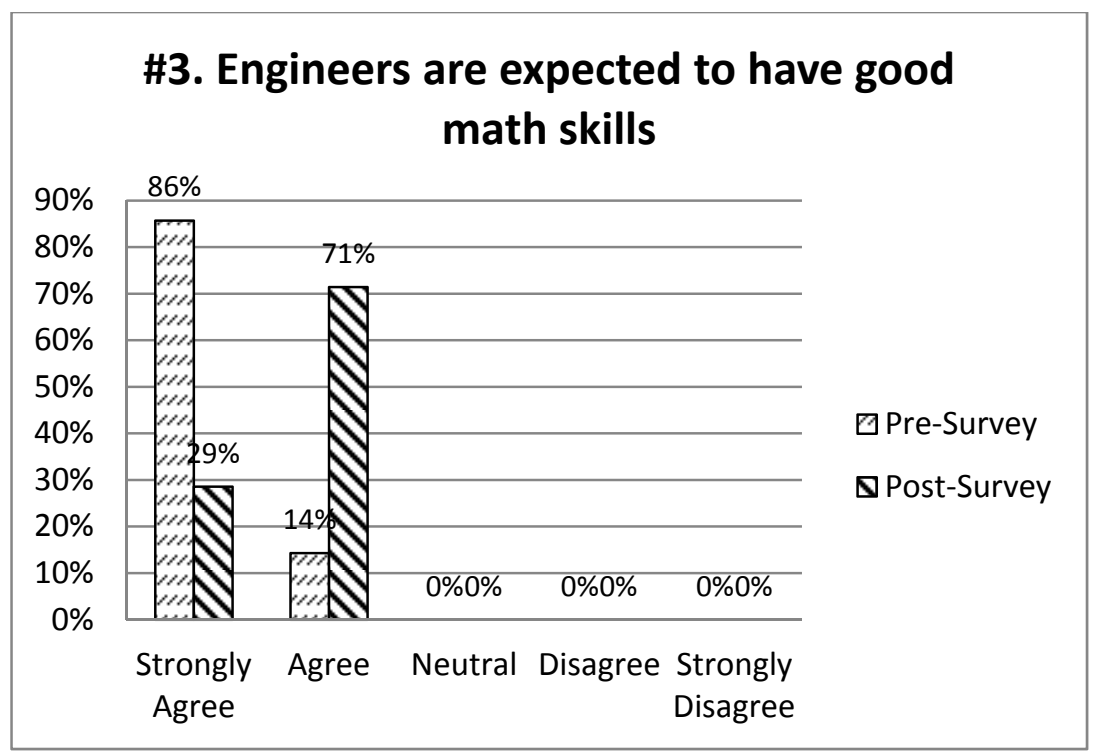

Figure 17: Survey question 3

$$
\begin{aligned}
& \text { D } \\
& \stackrel{0}{0} \\
& \mathbb{D} \\
& N \\
& \stackrel{+}{+} \\
& \overrightarrow{0} \\
& \overrightarrow{0}
\end{aligned}
$$




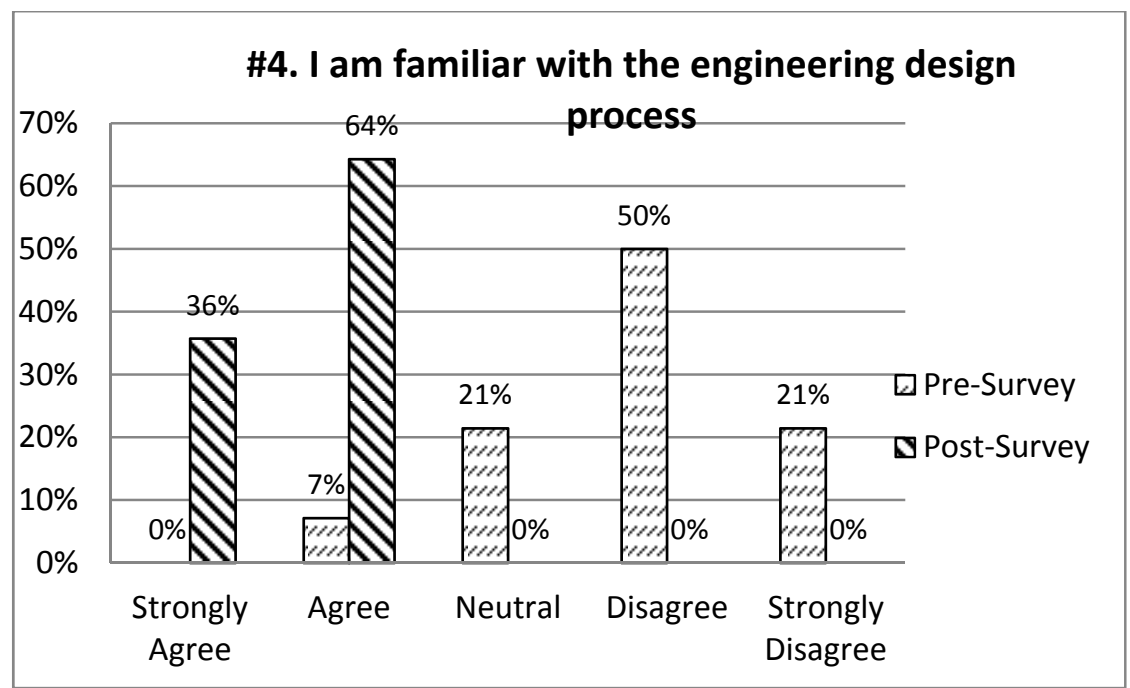

Figure 18: Survey question 4

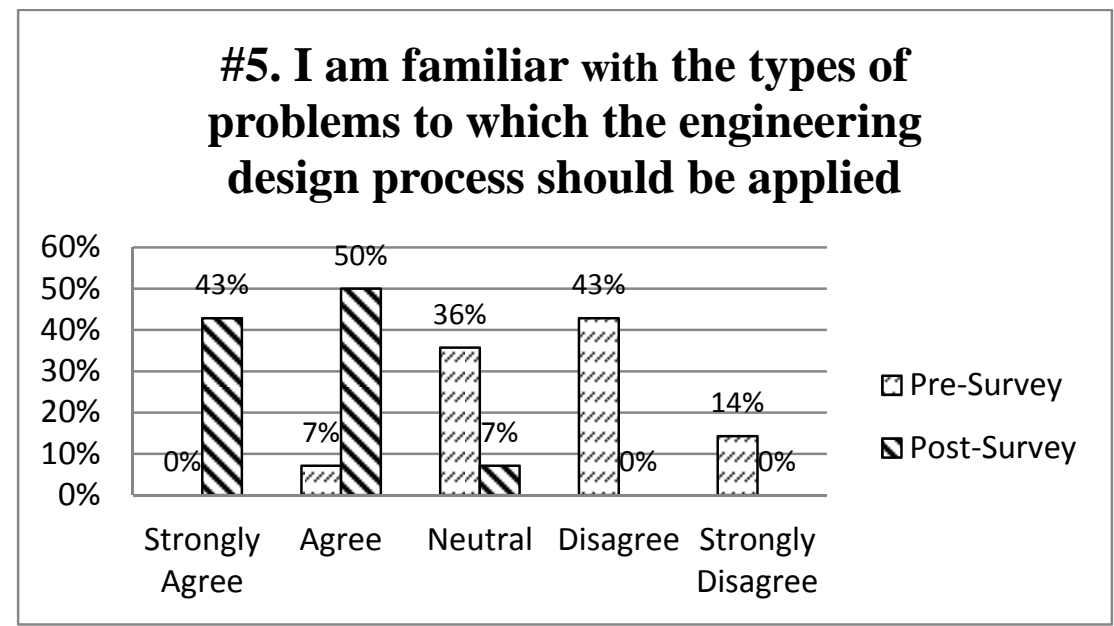

Figure 19: Survey question 5

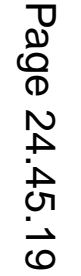




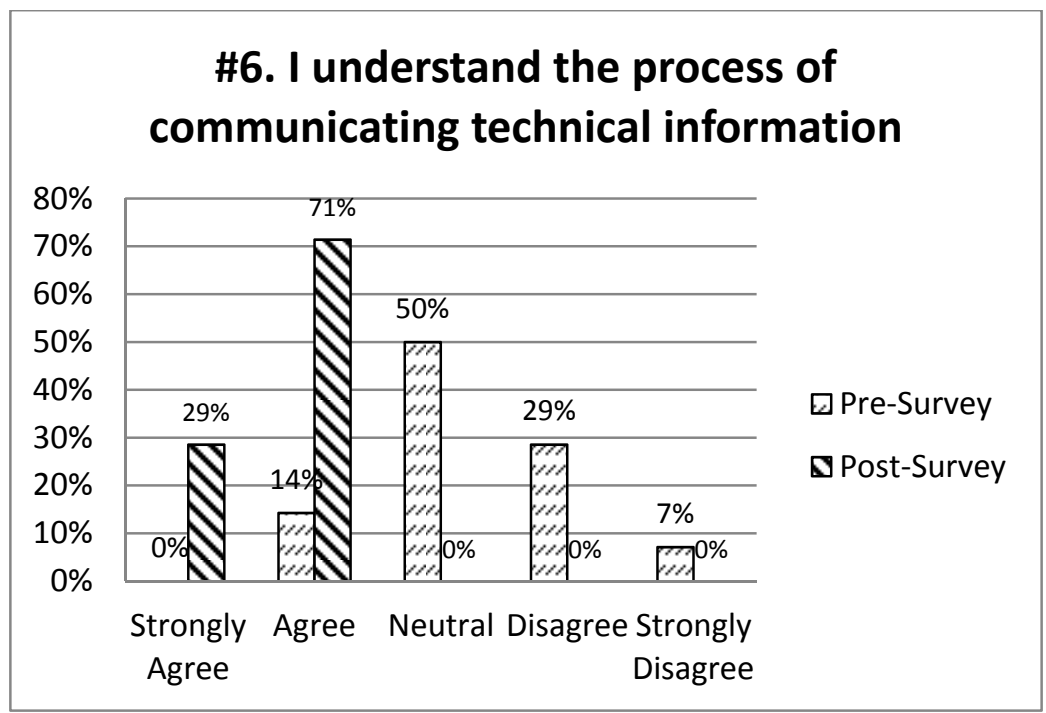

Figure 20: Survey question 6

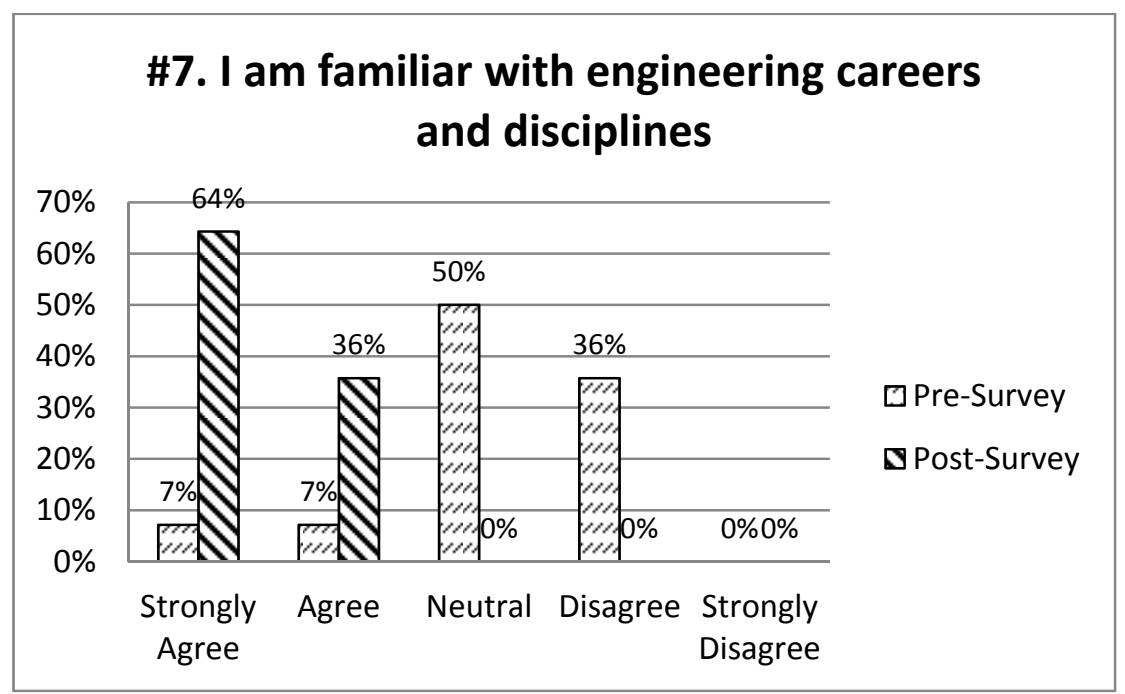

Figure 21: Survey question 7

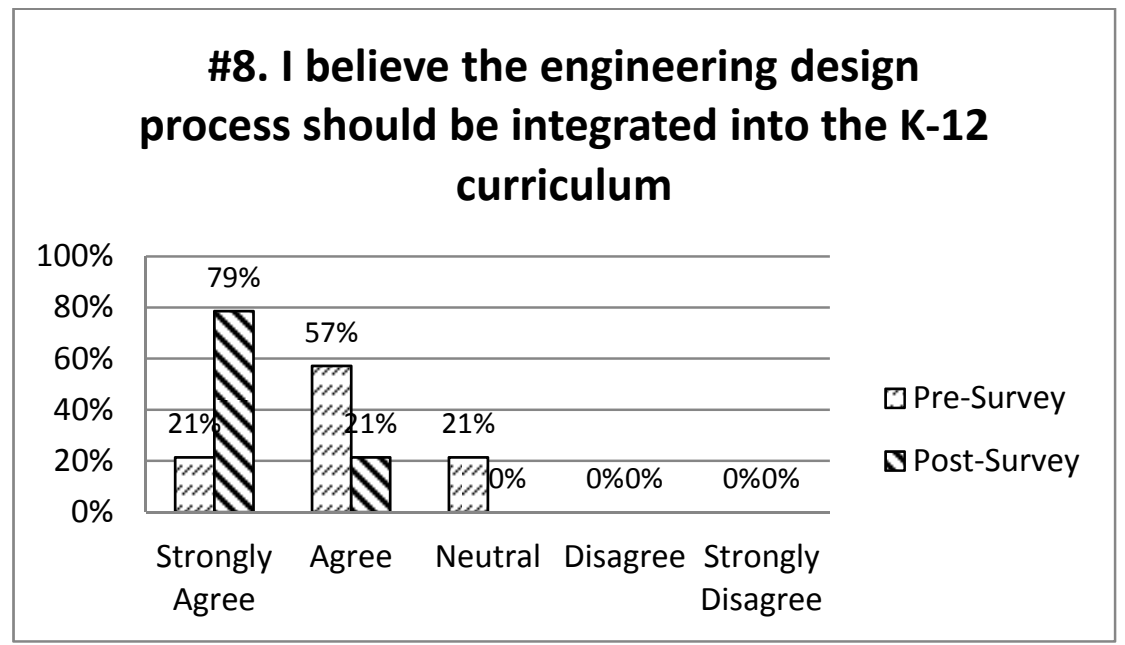


Figure 22: Survey question 8

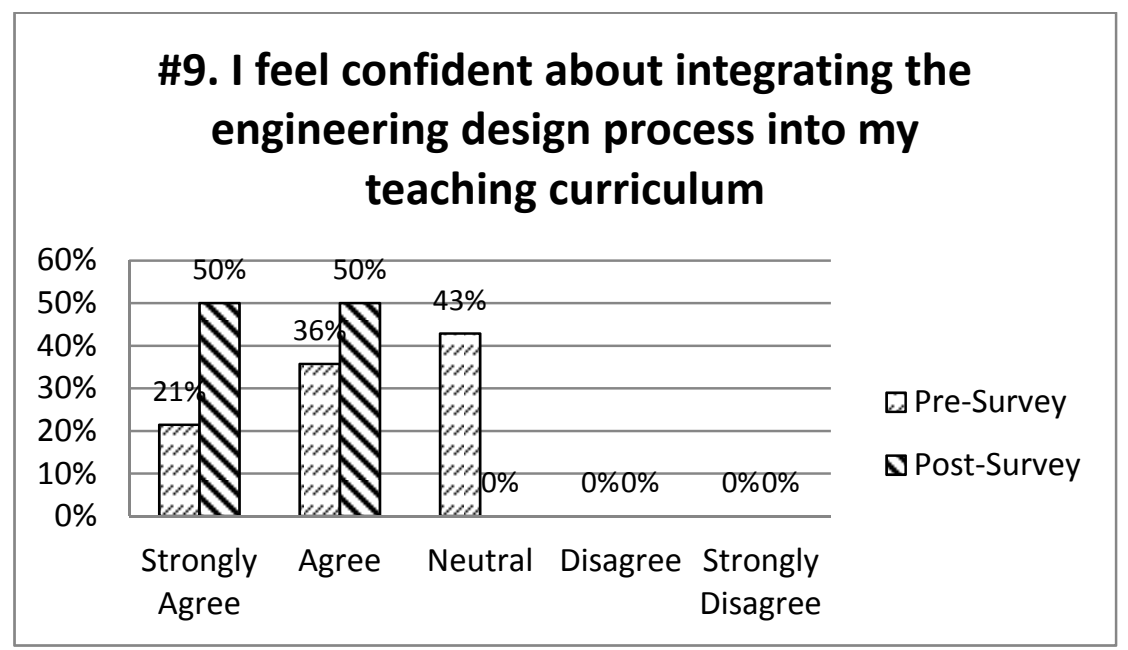

Figure 23: Survey question 9

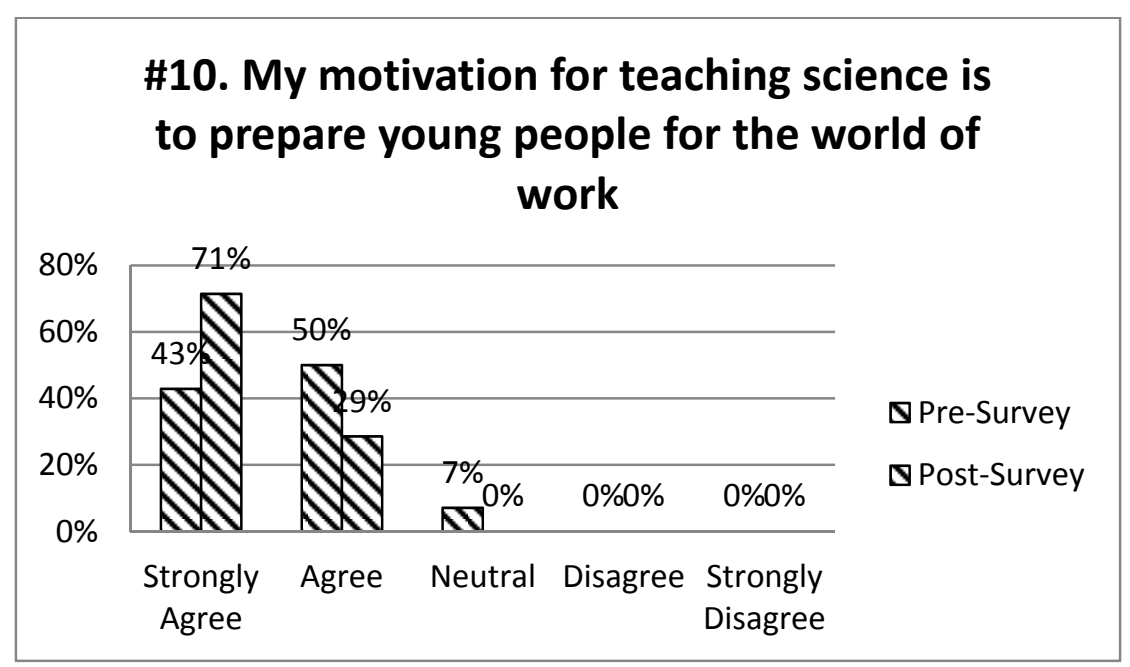

Figure 24: Survey question 10 


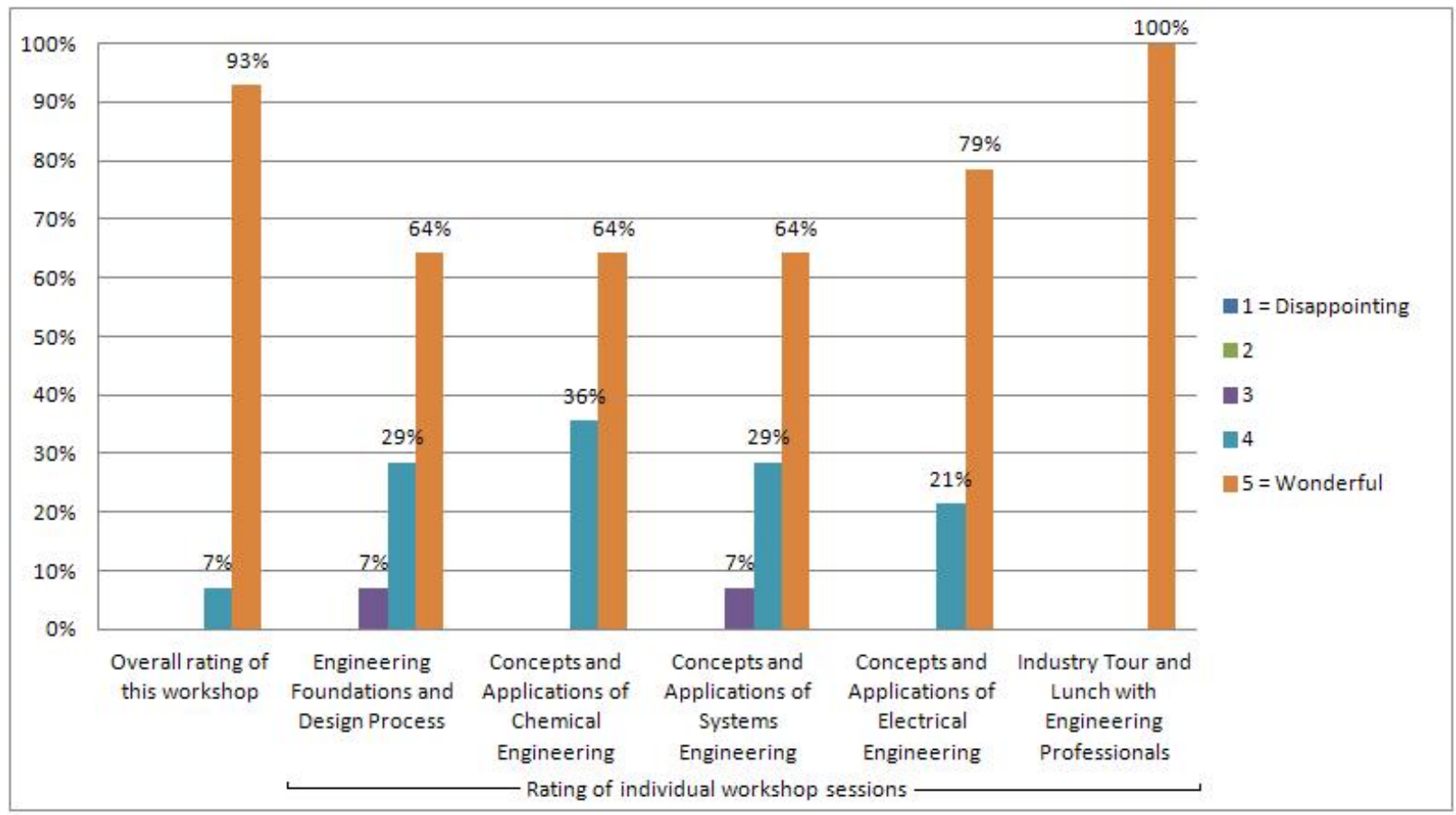

Figure 25: Post workshop survey about the individual sessions.

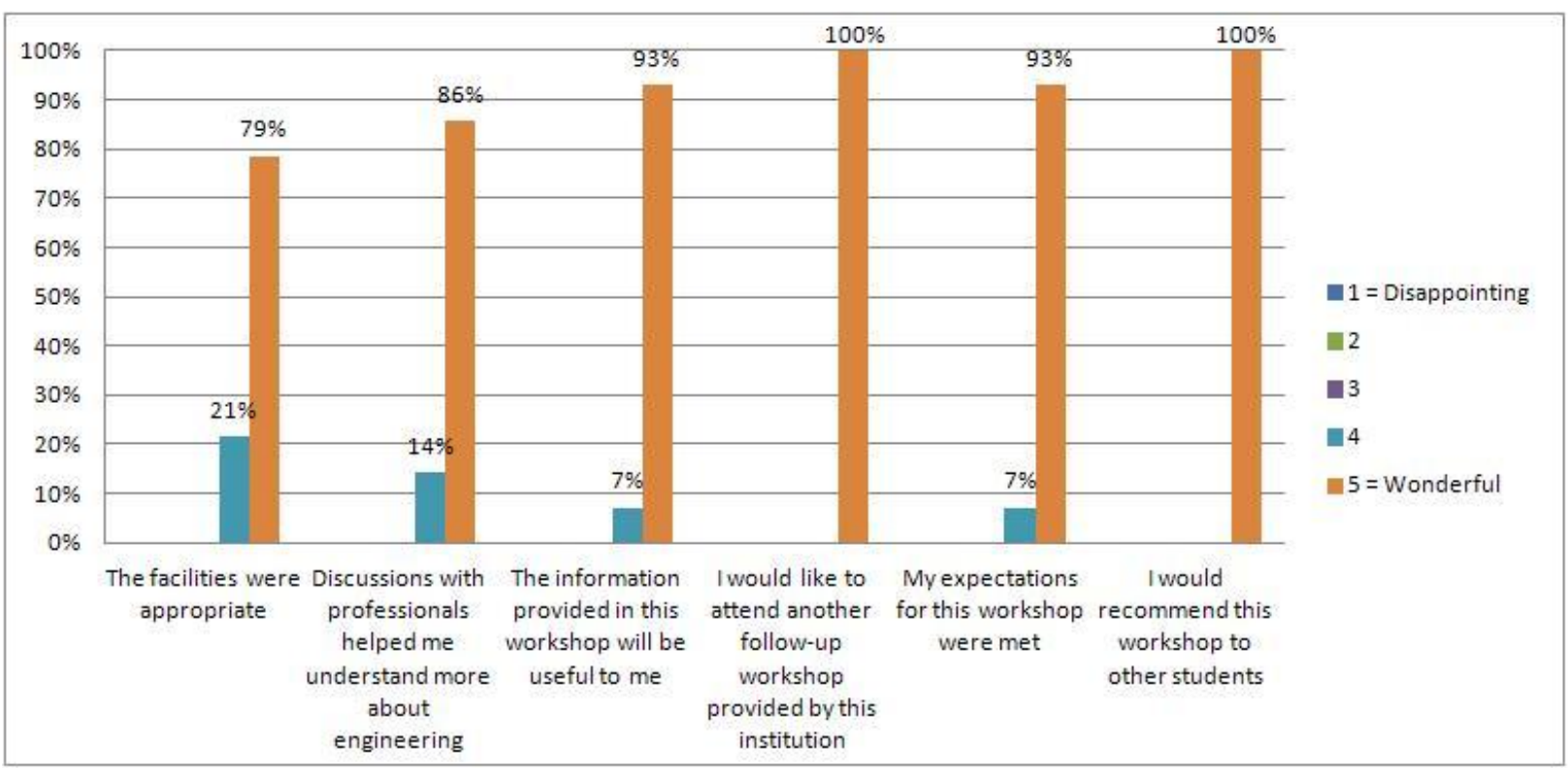

Figure 26: Post workshop survey about the overall experience.

\section{Conclusions and Future Recommendation}

In order to increase the number of minority, particularly Hispanic, students who choose to pursue a career in engineering after they graduate from high school, we created a workshop aimed at the senior pre-service students at TAMIU with the goal that by educating them in the different disciplines of engineering that they will intern encourage their future students to pursue one of these fields. This paper presents the details of the individual components of the workshop along with evaluation results performed using pre and post surveys. The pre and post surveys results 
indicate the workshop was successful in educating the pre-service teachers about the different fields of engineering. The survey results that were only given after the workshop indicate the participants liked the experience and found it useful.

It is recommended that this program be made permanent using local in-service teachers. The program can be offered in the summer as a one week workshop. Funding for this program will need to be considered however.

\section{Acknowledgement}

The authors like to show their heartfelt gratitude to the United States Department of Education for funding support, without which this workshop may never be organized. Also, the authors like to thank the reviewers for their careful review to improve the quality of the paper. Also, the authors like to thank Dr. Rafic A. Bachnak, Penn State University at Harrisburg, Dr. Daniel J. Mott, Dr. Rohitha Goonatilake, and Dr. Runchang Lin of Texas A\&M International University, Laredo, Texas for their support.

\section{References}

1. Snap Circuits by Elenco. URL: http://www.snapcircuits.net/

2. Austin, T. and Tanenbaum, A., Structured Computer Organization, $6^{\text {th }}$ Ed., Prentice Hall, 2012.

3. Hambley, A., Electrical Engineering Principles and Applications, 5th Ed., Pearson/Prentice Hall, 2008, ISBN: 0-13-198922-7.

4. Blanchard, B. S. and Fabrycky, W. J. , Systems Engineering and Analysis, $5^{\text {th }}$ Ed., Prentice Hall, Upper Saddle River, New Jersey, 2010.

5. Wasson, C. S., Systems Analysis, Design, and Development, Wiley and Sons, Hoboken, New Jersey, 2006.

6. INCOSE, “What is System Engineering?” June 14, 2004, URL: http://www.incose.org/practice/whatissystemseng.aspx.

7. NASA System Engineering Handbook, SP610S, June 1995, NASA, URL: http://www.stanford.edu/class/cee243/NASASE.pdf

8. Lambert, J. and Cox, J., Microsoft ${ }^{\circledR}$ Access ${ }^{\circledR} 2010$ Step by Step, Microsoft Press, O'Reilly Media, Inc., Cambridge, MA., 2010. 